\title{
Direct transparotid approach via a modified mini-preauricular incision for open reduction and internal fixation of subcondylar fractures
}

\author{
Jung-Soo Lee, Sang-Hoon Kang \\ Department of Oral and Maxillofacial Surgery, National Health Insurance Service Ilsan Hospital, Goyang, Korea
}

\begin{abstract}
J Korean Assoc Oral Maxillofac Surg 2021;47:327-334)
A transparotid approach, with a retromandibular or preauricular incision, is an alternative surgical approach for treating a subcondylar fracture and reducing the potential for complications such as injury to the facial nerves. However, retromandibular and preauricular incisions are both created far away from the parotid gland-dissection area. Thus, it is necessary to undermine the skin and retract it anteriorly to access the surgical field. Here, we introduce a modified approach wherein the incision allows for direct access to the fracture site. This approach may be adopted to shorten the incision length, reduce the retraction trauma at the surgical site, and help prevent injury to the facial nerve.
\end{abstract}

Key words: Mandibular fracture, Parotid gland, Facial nerve injury

[paper submitted 2020. 11. 30 / revised 2021. 1. 14 / accepted 2021. 2. 1]

\section{Introduction}

A subcondylar fracture is a common type of mandibular fracture $^{1}$. Treatments for subcondylar fractures have long been debated and extensively investigated ${ }^{2,3}$. Currently, there are two main treatment options for a subcondylar fracture: the closed reduction and the open reduction. The advantage of the former is that invasive surgery is not required; however, closed reductions are associated with higher complication rates relative to open reductions with fixation ${ }^{4}$. Thus, surgical procedures have been preferred for treating the subcondylar fracture $^{2}$.

Surgical procedures for subcondylar fracture are performed with two main approach options: via the oral cavity and extra-orally, via the skin. The intraoral approach boasts several advantages, including reducing the postsurgical facial scar, avoiding injury to facial nerves, and facilitating assessments of dental occlusion during surgery ${ }^{5}$. Nevertheless, it is a chal-

\footnotetext{
Sang-Hoon Kang

Department of Oral and Maxillofacial Surgery, National Health Insurance Service Ilsan Hospital, 100 Ilsan-ro, Ilsandong-gu, Goyang 10444, Korea TEL: +82-31-900-0267

E-mail:omskang@nhimc.or.kr

ORCID: https://orcid.org/0000-0003-3335-3040
}

(c) This is an open-access article distributed under the terms of the Creative Commons Attribution Non-Commercial License (http://creativecommons.org/ licenses/by-nc/4.0/), which permits unrestricted non-commercial use, distribution, and reproduction in any medium, provided the original work is properly cited.

Copyright $\odot 2021$ The Korean Association of Oral and Maxillofacial Surgeons. lenging technique to adopt, requires specialized instruments, and the surgeon must have additional training. In contrast, various extraoral approaches, including the retromandibular, Risdon, and periauricular approaches ${ }^{6}$, also exist, yet the drawbacks of an extraoral approach are that it can leave a significant facial scar and/or cause facial nerve damage $e^{2}$. Meanwhile, treating a subcondylar fracture with a transparotid approach may reduce the probability of complications such as facial nerve injuries ${ }^{7-9}$. Using this method, the parotid gland is dissected in the area where the facial nerve branches diverge. However, both the retromandibular and preauricular incisions are established quite distantly from the parotid gland dissecting area; thus, the skin must be undermined and retracted anteriorly to access the surgical field.

The present study aimed to develop a modified approach wherein an incision is created close to the fracture site, allowing more direct access. We reasoned that this approach could prevent injury to the facial nerve, necessitate a shorter incision, and reduce the degree of retraction trauma at the surgical site.

\section{Technical Note}

A 22-year-old male visited our hospital due to a traumatic injury. He had no specific medical history. Based on a facial computed tomography scan, he was diagnosed with a right 
subcondylar fracture and a symphysis fracture in the mandible. Two days after the injury, an open reduction and internal fixation was performed at the fracture site under general anesthesia. For the mandibular symphysis fracture, an incision was made in the labial vestibule area of the anterior mandible to expose the fracture site. Then, after dental occlusion was confirmed, an internal fixation procedure was performed.

Next, for the subcondylar fracture, a landmark line was drawn horizontally to mark the incision for the open reduction, starting at the level of the inferior earlobe and running parallel to the Frankfort horizontal plane. Then, another line was drawn, $1 \mathrm{~cm}$ anterior to and parallel to the line, where an incision is typically made for the conventional preauricular approach.(Fig. 1. A) At the intersection of the two lines, an incision smaller than $2 \mathrm{~cm}$ in length was created inferior to the earlobe, in the direction of the superficial musculoaponeurotic system (SMAS). After making the skin incision, we dissected the subcutaneous tissue and the SMAS to expose the capsule of the parotid gland.(Fig. 1. B) As the buccal branch of the facial nerve passes horizontally, within the parotid gland, we determined that it would be preferable to first make the incision of the gland capsule horizontally (dotted line) (Fig. 1. B), then proceed with the dissection.

In this case, it was necessary to dissect the parotid gland carefully, and, by cutting deeper, the masseter muscle was exposed.(Fig. 2) From the masseter muscle, a new incision was made that changed the direction of the ongoing dissection to avoid cutting the masseter muscle horizontally (dotted line). (Fig. 2) This new incision was an oblique, vertical incision, which ran along the anterior and posterior aspects of the masseter muscle fibers. Then, a dissection was performed to sep-

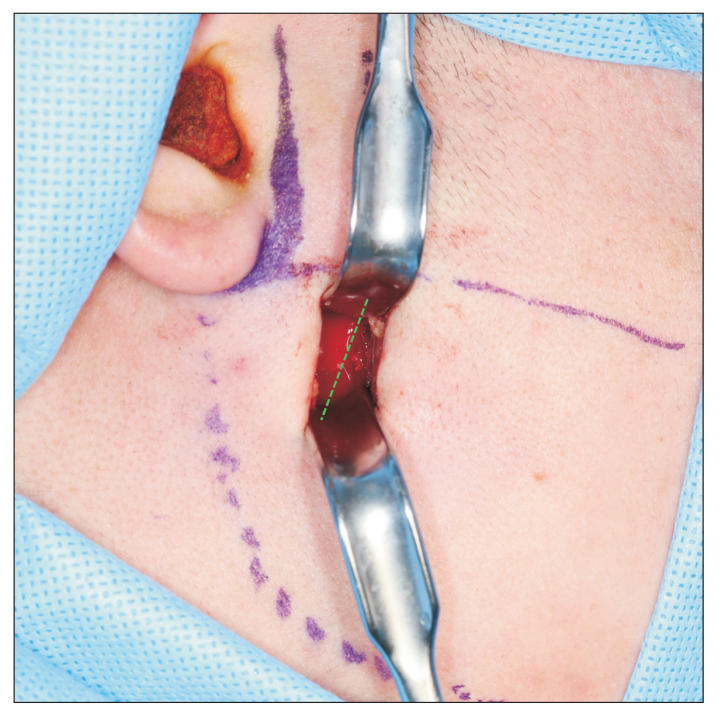

Fig. 2. The masseter muscles. As the dissection continued, the masseter muscles were encountered. They were dissected obliquely (green dotted line), parallel to the masseter muscle fibers anteriorly and posteriorly.

Jung-Soo Lee et al: Direct transparotid approach via a modified mini-preauricular incision for open reduction and internal fixation of subcondylar fractures. J Korean Assoc Oral Maxillofac Surg 2021
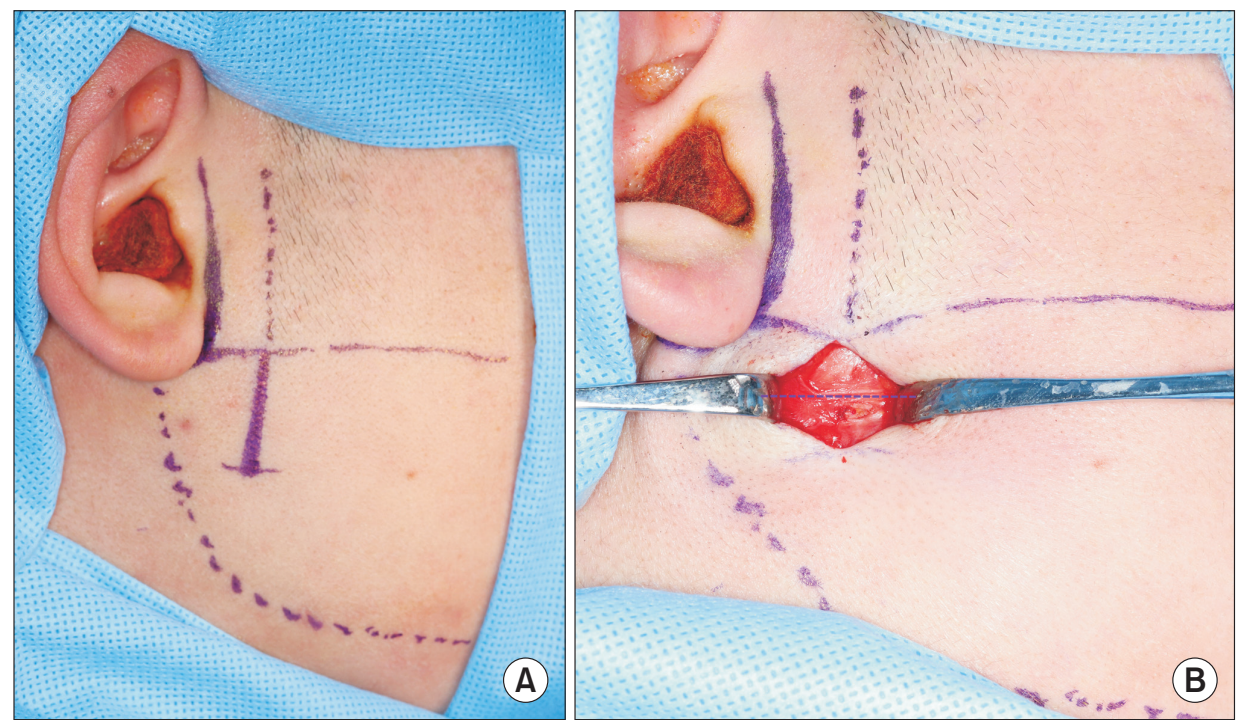

Fig. 1. A. Landmark line for the skin incision. A line was drawn, $2 \mathrm{~cm}$ long, at $1 \mathrm{~cm}$ anterior to and parallel to the placement of a conventional preauricular incision. It was located immediately below the earlobe, parallel to the Frankfort horizontal plane. B. Skin incision. The incision is less than $2 \mathrm{~cm}$ long, made inferior to the earlobe in the direction of the superficial musculoaponeurotic system. The parotid capsule incised horizontally (purple dotted line), and the parotid tissues were bluntly dissected open with vessel forceps.

Jung-Soo Lee et al: Direct transparotid approach via a modified mini-preauricular incision for open reduction and internal fixation of subcondylar fractures. J Korean Assoc Oral Maxillofac Surg 2021 


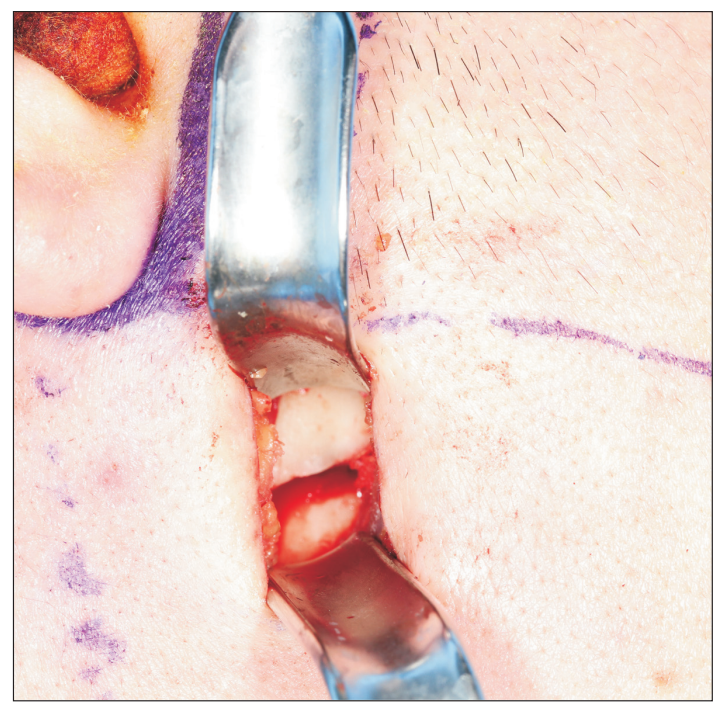

Fig. 3. The periosteum dissection. The periosteum was dissected superiorly and inferiorly, and the fracture site was exposed for a short distance, with retraction.

Jung-Soo Lee et al: Direct transparotid approach via a modified mini-preauricular incision for open reduction and internal fixation of subcondylar fractures. J Korean Assoc Oral Maxillofac Surg 2021 arate the periosteum, superiorly and inferiorly, to gain a direct view of the fracture line in the subcondyle. When the fracture lines of the subcondyle were exposed (Fig. 3), we checked that the dental occlusion of the patient was acceptable. Next, the fractured mandibular subcondyle area was treated with two, four-hole metal mini-plates, fixed with 6-mm screws (Jeil Medical, Seoul, Korea).(Fig. 4)

After the internal fixation, the dental occlusion of the patient was checked once again, and the wound was closed. The periosteum and the masseter muscle were sutured with 4-0 absorbable polyglactin sutures in a simple, interrupted pattern; the same method was also used to suture the parotid gland and the surrounding capsule. The loose areolar tissue above the capsule and the SMAS layer was then sutured in a simple, interrupted pattern, while the skin and the subcutaneous tissue were finally sutured with a continuous subcutaneous method.

Immediately after the surgery, the patient did not show any signs of complications, including facial nerve injury. The
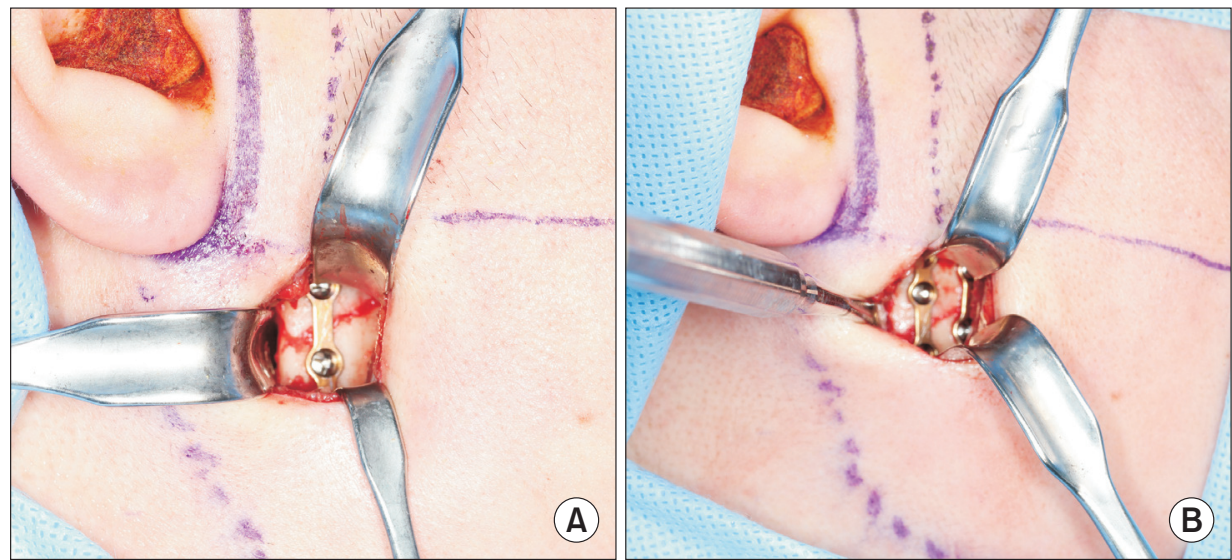

Fig. 4. A. Reduction and fixation of the fracture. A four-hole mini-plate was fixed under retraction with a posterior, sigmoidal area and inferior direction. B. Fractured mandibular subcondyle repair. The fractured area was fixed with two four-hole metal mini-plates and 6-mm screws, after confirming that the dental occlusion was favorable.

Jung-Soo Lee et al: Direct transparotid approach via a modified mini-preauricular incision for open reduction and internal fixation of subcondylar fractures. J Korean Assoc Oral Maxillofac Surg 2021
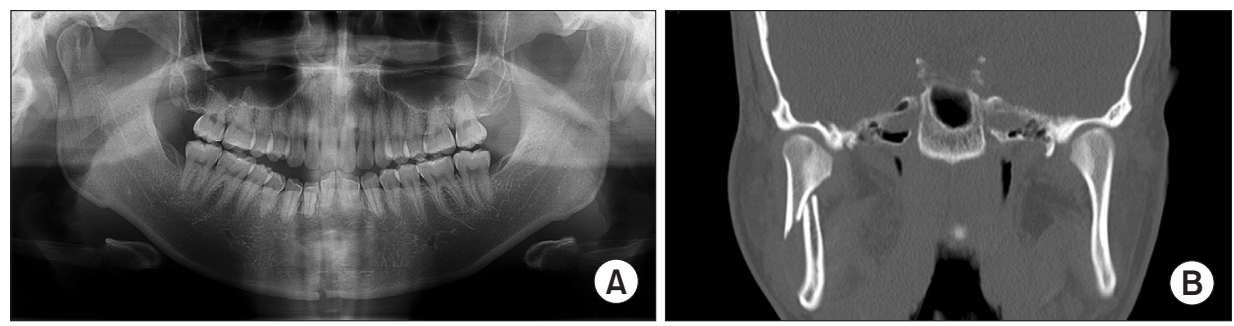

Fig. 5. A. Panoramic radiograph taken preoperatively of the 22-year-old patient. B. Coronal view of a computed tomography scan taken preoperatively of the 22-year-old patient.

Jung-Soo Lee et al: Direct transparotid approach via a modified mini-preauricular incision for open reduction and internal fixation of subcondylar fractures. J Korean Assoc Oral Maxillofac Surg 2021 
fractured sites were well reduced (Fig. 5, 6), and the patient reported no discomfort; subsequently, he was discharged. The

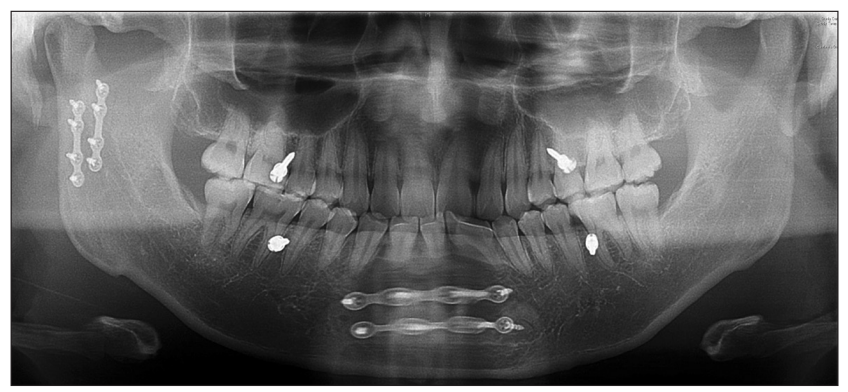

Fig. 6. Panoramic radiograph taken immediately postoperatively in the 22-year-old patient. The image shows good reduction of the subcondyle fracture.

Jung-Soo Lee et al: Direct transparotid approach via a modified mini-preauricular incision for open reduction and internal fixation of subcondylar fractures. J Korean Assoc Oral Maxillofac Surg 2021

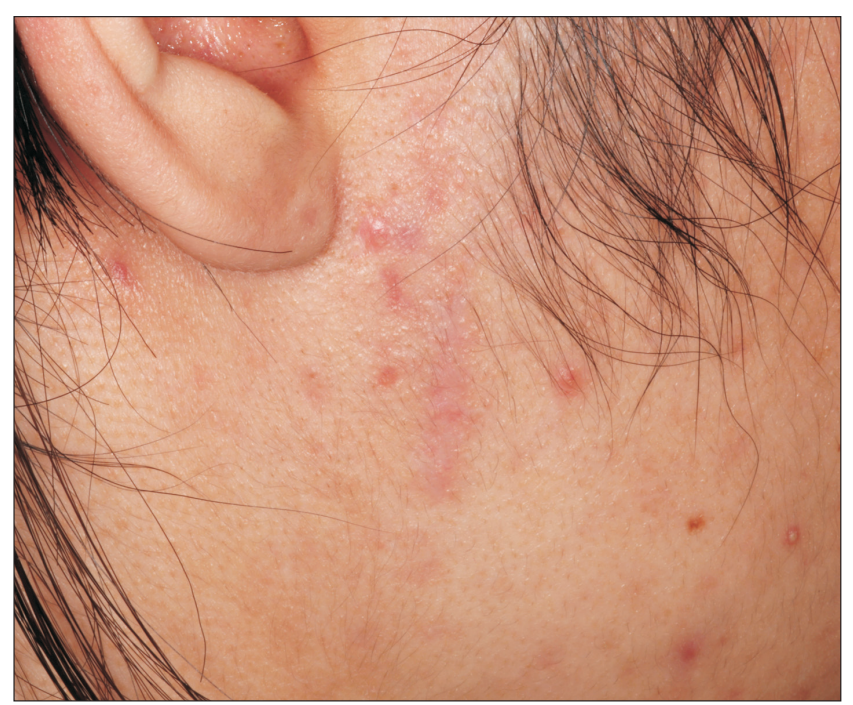

Fig. 7. Seven-month outcome of surgery for a subcondyle fracture in the 22-year-old patient. No significant postsurgical scar was visible at the skin incision site after seven months.

Jung-Soo Lee et al: Direct transparotid approach via a modified mini-preauricular incision for open reduction and internal fixation of subcondylar fractures. J Korean Assoc Oral Maxillofac Surg 2021 stitches were removed on postoperative day 7 , and the patient was followed up with as an outpatient at one, three, and seven months after surgery. At seven months, no substantial postsurgical scar was observed at the extraoral incision site of the subcondyle fracture surgery (Fig. 7), and the fractured bones in the mandible had healed well.

Separately, another patient, a 37-year-old male, visited our hospital due to traumatic injury. This patient was diagnosed with a right subcondylar fracture and a symphysis fracture of the mandible. He was treated with the same surgical approach described above. The fractured mandibular subcondyle area was fixed with one four-hole metal mini-plate and 6-mm screws (Jeil Medical). Immediately after his surgery, this patient also did not show any signs of complications, including facial nerve injury. The fractured site was reduced well (Fig. $8,9)$, and the patient was discharged without discomfort. He was followed up as an outpatient after one, three, and seven months and, at seven months after the subcondyle fracture surgery, no visible postsurgical scar at the extraoral incision site was observed.(Fig. 10)

\section{Discussion}

The present study introduces a novel transparotid approach for treating a subcondylar fracture. Unlike the existing intraoral approach, which involves a narrow surgical field, a wide dissection, and severe retraction ${ }^{5}$, a transparotid approach is based on a dissection in the area where the facial nerve branches diverge; thus, it reduces the risk of facial nerve morbidity. However, in our novel transparotic approach, the location of the incision line was different from those drawn in previous transparotid approaches that require either a preauricular or a retromandibular incision ${ }^{10,11}$.

Use of a preauricular incision can avoid the need for severe retraction force; however, the incision can be located too high
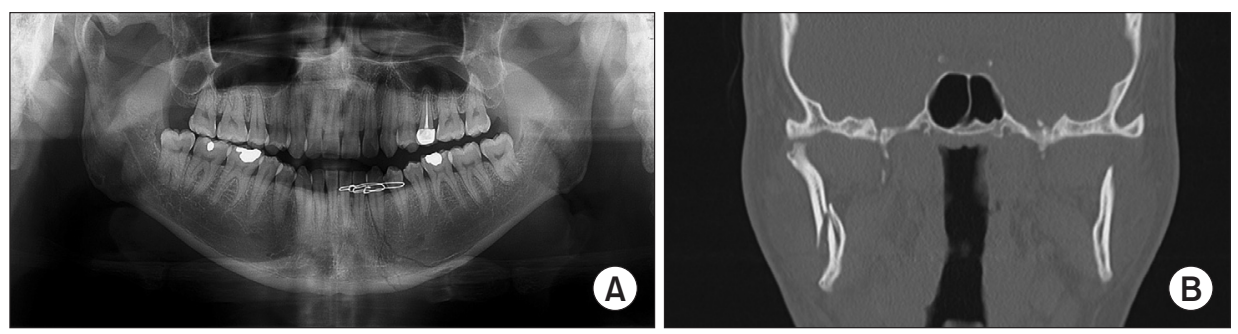

Fig. 8. A. Panoramic radiograph taken preoperatively of the 37-year-old patient. B. Coronal view of a computed tomography scan taken preoperatively of the 37 -year-old patient.

Jung-Soo Lee et al: Direct transparotid approach via a modified mini-preauricular incision for open reduction and internal fixation of subcondylar fractures. J Korean Assoc Oral Maxillofac Surg 2021 


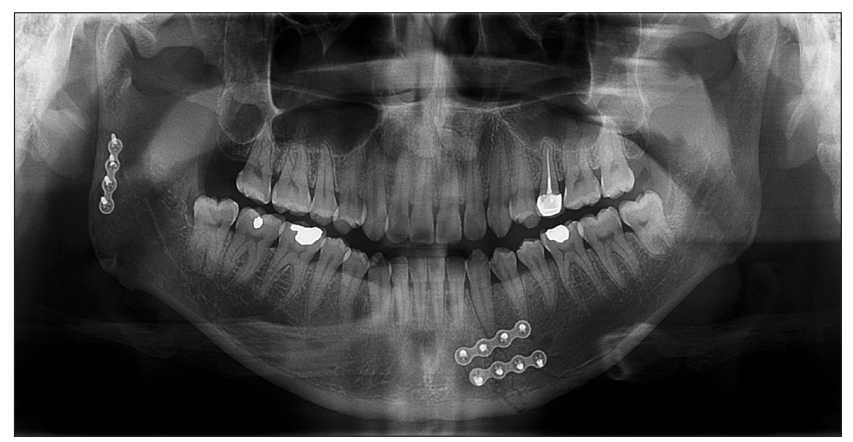

Fig. 9. Panoramic radiograph taken immediately postoperatively in the 37-year-old patient. The image shows good reduction at the fractured sites in the mandible.

Jung-Soo Lee et al: Direct transparotid approach via a modified mini-preauricular incision for open reduction and internal fixation of subcondylar fractures. J Korean Assoc Oral Maxillofac Surg 2021

for managing low subcondylar fractures; thus, it may only be applicable in the treatment of high condylar fractures'. The extraoral approach to subcondylar fractures can be classified as high, middle, or low, according to the location ${ }^{12}$. A fracture with a high location can be repaired with the preauricular and the perilobular approaches, which involve making a vertical incision anterior to the ear for access to the fracture site. A fracture with a middle location can be repaired with the retromandibular approach, which involves creating an incision along the posterior border of the mandible, under the earlobe. The retromandibular transparotid approach provides direct access to the fractured area because the distance from the incision line to the fractured site is short and there is no masseter muscle in the dissecting course; notably, this is the only approach that allows an incision close to the fracture line ${ }^{9}$. However, the retromandibular incision is close to the area where the facial nerve divides to form the temporofacial branch, which comprises the temporal and zygomatic branches, and the cervicofacial branch, which comprises the buccal, marginal mandibular, and cervical branches ${ }^{13,14}$. Thus, when the surgical window is located between the buccal and marginal mandibular branches, a more superior retraction is required for fixing the condylar fragments, which can cause facial nerve morbidity. Moreover, when advancing from the retromandibular incision, moving in the forward direction over the parotid gland requires excessive retraction, and, thus, the dissection may adversely affect the facial nerve within the parotid gland ${ }^{15}$. Meanwhile, a fracture with a low location can be repaired using the Risdon approach or a submandibular approach, wherein a horizontal incision is made along the inferior mandibular border. However, none of these approaches provide direct access to a subcondylar fracture site, and they

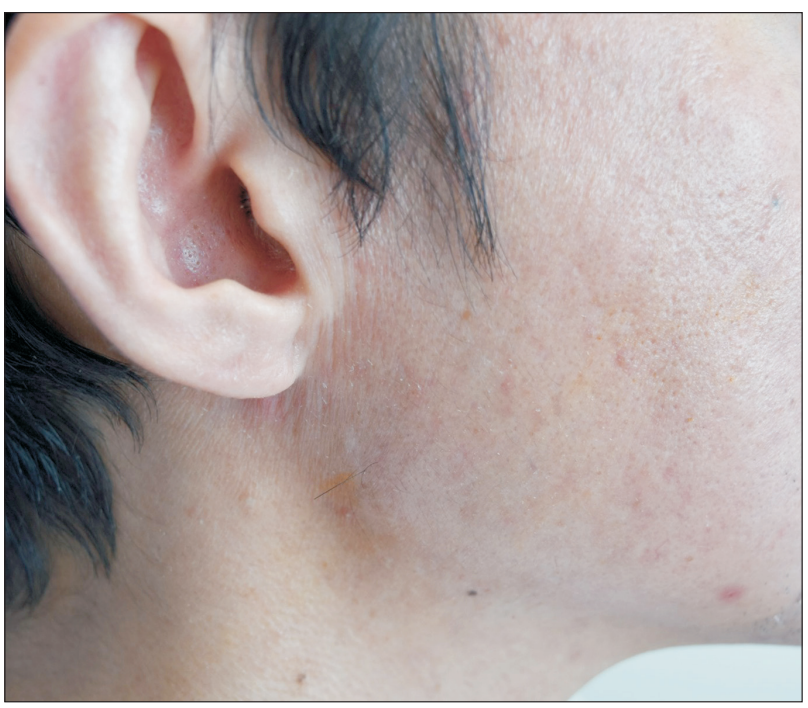

Fig. 10. Seven-month surgical outcome of the subcondyle fracture in the 37-year-old patient. No postsurgical scar was visible at the skin incision site after seven months.

Jung-Soo Lee et al: Direct transparotid approach via a modified mini-preauricular incision for open reduction and internal fixation of subcondylar fractures. J Korean Assoc Oral Maxillofac Surg 2021

all require a dissection of the parotid gland. Therefore, the advantage of our new approach is the capacity for a direct approach to the fracture site.

Our novel approach for repairing a subcondylar fracture required an incision anterior and inferior to the location of a preauricular incision. Thus, the incision was established in an area where the facial nerve diverges widely, with ample space between the temporofacial and cervicofacial branches. Additionally, creation of a mini-incision is possible because the short distance to the subcondylar fracture site reduces the amount of retraction required to visualize the surgical field directly.

In the present study, we described only two cases of condylar repair conducted using our new approach. Thus, due to limited data, it is difficult to perform a statistical comparison between this approach and previous transparotid approaches completed via a preauricular or retromandibular incision. However, neither of our patients experienced complications; in both cases, no facial nerve palsy or unfavorable facial scars were observed. Moreover, this approach was easy to perform, without issues due to the retraction force. Thus, we recommend that surgeons should consider using this method for treating subcondylar fractures.

Hematoma, facial nerve weakness, salivary fistula, and wound infection have been reported as complications in mandibular condylar fracture surgery conducted using the conventional transparotid approach ${ }^{7,8,16,17}$. Similarly, the novel 
approach presented in this case crosses the parotid, and, as with the previous approach, the possibility of facial nerve injury cannot be fully excluded. However, in cases of incisions that are performed from the rear, such as retromandibular and preauricular incisions, which are conventional methods in the parotid approach, a long incision line for traction to the parotid gland and excessive retraction are required. In contrast, this approach involves making a skin incision $1 \mathrm{~cm}$ anterior to the preauricular incision, which is the area where the parotid line is located. Since the skin incision line is relatively shorter than the retromandibular or preauricular incision lines and does not require excessive retraction, chance of damage to facial nerves is considered to be relatively small.

When adopting the method where the parotid gland is penetrated while tractioning through the posterior incision, the area passing through the parotid gland may be found adjacent to the posterior skin incision line. This is in proximity to the main branch of the facial nerve, and the possibility of facial nerve damage may be higher than that in the case where surgery is performed on the area where the facial nerve is divided and opened.

This method is applied at a location that is in front of the existing skin incision line and is separated from structures such as the ear; therefore, it has the aesthetic disadvantage of scarring. Although the length of the incision line may be shorter than that of a retromandibular or preauricular incision, aesthetics may be reduced owing to the location of the incision line; however, the results are adequate, as was observed in these two cases. In this regard, this method may have fewer aesthetic disadvantages than expected that are sufficiently limited enough to allow scar formation to be accepted clinically.

Comparative studies on scar patterning and patients' aesthetic satisfaction with new and existing transparotid approaches remain lacking. After surgery using this method and the existing skin incisions, detailed additional research on scarring may be necessary. In this regard, intensive research using the patient and observer scar assessment scale (POSAS) is required ${ }^{18}$. However, in this study, the scar of the relevant incision line was clinically insignificant and was therefore difficult to distinguish; the location may not depict a significant problem aesthetically. Eventually, if the difference in aesthetics between the existing incision and the skin incision presented by this method is deemed nonsignificant, this surgical approach can be generalized.

However, as the verification is not yet clear, the scar can be minimized using careful consideration of the suture method and surgeon's skill. Patients with mandibular condyle fractures should be completely informed about the advantages and disadvantages of this surgical approach to enable them to make choices. Since there is less tissue trauma owing to the need for less traction during surgery, complications such as wound infection and delayed healing are also expected to occur less frequently at the surgical site. However, as compared with the existing approach, since the incision line is positioned more anteriorly or below the preauricular area, further evaluation of the scar and patient's aesthetic satisfaction is deemed necessary.

In the case of a conventional retromandibular or preauricular incision, the parotid gland is dissected after the skin incision and then penetrated after traction. There is a high possibility of bleeding owing to the presence of the temporal artery vein. The novel method can be directly applied using a small incision and is far from the blood vessels above; therefore, bleeding is likely to be insignificant during facial surgery. In particular, since the masseter muscle is pulled according to the direction of muscle movement to approach the surgical site, almost no bleeding may occur during surgery, providing a good surgical field of view.

For this approach, the skin incision line was located $1 \mathrm{~cm}$ anterior to the conventional incision line made with the preauricular approach and inferior to the imaginary horizontal line traversing the earlobe. After creating a vertical incision of less $2 \mathrm{~cm}$ in length to the depth of the SMAS, the incision line changed direction to run horizontally, through the parotid capsule. We determined that a horizontal incision at the gland capsule was preferable to facilitate the dissection because the buccal branch of the facial nerve passes horizontally through the parotid gland ${ }^{14}$. Moreover, the inferior part of the buccal branch has the lowest probability of anatomical variations. Therefore, we reasoned that this new approach should significantly reduce the risk of facial nerve injury. In addition, severe retraction of the tissue around the parotid gland was unnecessary because the dissection provided direct access to the subcondylar fracture site. Thus, this approach can reduce facial nerve morbidity. Moreover, after passing the parotid gland, in the muscular layer dissection, the muscles were preserved by redirecting the incision line obliquely, along the masseter muscle fibers.

After passing the masseter muscle, the fracture lines were directly visible, which made it easier to locate the fractured fragment. Then, after internal fixation, sutures were performed by working backward, starting with the masseter muscle, then the parotid gland and the SMAS. Next, the loose 
areolar tissue above the capsule and the SMAS layer was sutured in a simple interrupted pattern. Finally, the skin and the subcutaneous tissue were sutured with a continuous subcutaneous method to minimize the postsurgical scar ${ }^{19}$.

This new approach could have an aesthetic disadvantage because the incision line was anterior and inferior to the conventional preauricular incision line. Nevertheless, the current approach method we chose resulted in healing without any visible scarring in both our patients. With this approach, the subcondylar region is directly visible when the parotid gland is exfoliated. Therefore, it is judged to be an approach that facilitates direct viewing of the fracture site in cases of subcondylar fracture. The surgical field is also tolerable tolerable with the conventional transparotid approach through upper and lower retraction of the parotid gland. However, in high condylar fractures such as that in the condylar head or neck, the approach field of view may be narrow as it is located below the fracture site. In these cases, the transparotid approach was advantageous as it had an adequate field of view, with an effect on the ease of surgery, even when the condyle fracture split segment overlaps laterally with the ramus fracture segment. As observed in these cases, the surgical field of view using our novel technique seems to be better than that in any other approach.

In conclusion, we herein described a novel approach for treatment of a subcondylar fracture. With this approach, the incision is made anterior and inferior to the conventional preauricular incision. Our proposed approach provides direct access to the subcondylar fracture site, which facilitates an open reduction and internal fixation. The two patients described experienced no complications, and the approach was adopted without any issues. Thus, we recommend this extraoral method for treating subcondylar fractures, particularly in cases with a low probability of aesthetic problems.

\section{ORCID}

Jung-Soo Lee, https://orcid.org/0000-0001-9162-1985

Sang-Hoon Kang, https://orcid.org/0000-0003-3335-3040

\section{Authors' Contributions}

J.S.L. and S.H.K. obtained data and wrote the manuscript. J.S.L. and S.H.K. drafted the manuscript. J.S.L. and S.H.K. participated in article design and coordination and carefully reviewed and revised the manuscript. All the authors read and approved the final manuscript.

\section{Ethics Approval and Consent to Participate}

The study was approved by the Institutional Review Board of National Health Insurance Service Ilsan Hospital (No. NHIMC 2020-11-011), and the informed consent was waived by the IRB.

\section{Conflict of Interest}

No potential conflict of interest relevant to this article was reported.

\section{References}

1. Rashid A, Eyeson J, Haider D, van Gijn D, Fan K. Incidence and patterns of mandibular fractures during a 5-year period in a London teaching hospital. Br J Oral Maxillofac Surg 2013;51:794-8. https://doi.org/10.1016/j.bjoms.2013.04.007

2. Kang DH. Surgical management of a mandible subcondylar fracture. Arch Plast Surg 2012;39:284-90. https://doi.org/10.5999/ aps.2012.39.4.284

3. Haug RH, Assael LA. Outcomes of open versus closed treatment of mandibular subcondylar fractures. J Oral Maxillofac Surg 2001;59:370-5; discussion 375-6. https://doi.org/10.1053/ joms.2001.21868

4. Worsaae N, Thorn JJ. Surgical versus nonsurgical treatment of unilateral dislocated low subcondylar fractures: a clinical study of 52 cases. J Oral Maxillofac Surg 1994;52:353-60; discussion 360-1. https://doi.org/10.1016/0278-2391(94)90436-7

5. Kang SH, Choi EJ, Kim HW, Kim HJ, Cha IH, Nam W. Complications in endoscopic-assisted open reduction and internal fixation of mandibular condyle fractures. Oral Surg Oral Med Oral Pathol Oral Radiol 2012;113:201-6. https://doi.org/10.1016/ j.tripleo.2011.02.005

6. Nam SM, Lee JH, Kim JH. The application of the Risdon approach for mandibular condyle fractures. BMC Surg 2013;13:25. https:// doi.org/10.1186/1471-2482-13-25

7. Van Hevele J, Nout E. Complications of the retromandibular transparotid approach for low condylar neck and subcondylar fractures: a retrospective study. J Korean Assoc Oral Maxillofac Surg 2018;44:73-8. https://doi.org/10.5125/jkaoms.2018.44.2.73

8. Kanno T, Sukegawa S, Tatsumi H, Karino M, Nariai Y, Nakatani E, et al. Does a retromandibular transparotid approach for the open treatment of condylar fractures result in facial nerve injury? J Oral Maxillofac Surg 2016;74:2019-32. https://doi.org/10.1016/ j.joms.2016.05.022

9. Bhutia O, Kumar L, Jose A, Roychoudhury A, Trikha A. Evaluation of facial nerve following open reduction and internal fixation of subcondylar fracture through retromandibular transparotid approach. Br J Oral Maxillofac Surg 2014;52:236-40. https://doi. org/10.1016/j.bjoms.2013.12.002

10. Liao HT, Wang PF, Chen CT. Experience with the transparotid approach via a mini-preauricular incision for surgical management of condylar neck fractures. J Craniomaxillofac Surg 2015;43:1595601. https://doi.org/10.1016/j.jcms.2015.07.023

11. Shi D, Patil PM, Gupta R. Facial nerve injuries associated with the retromandibular transparotid approach for reduction and fixation of mandibular condyle fractures. J Craniomaxillofac Surg 2015;43:402-7. https://doi.org/10.1016/j.jcms.2014.12.009

12. Knepil GJ, Kanatas AN, Loukota RJ. Classification of surgical approaches to the mandibular condyle. Br J Oral Maxillofac Surg 
2011;49:664-5. https://doi.org/10.1016/j.bjoms.2011.02.009

13. Ruiz R, Schlund M, Raoul G, Kyheng M, Fontaine C, Nicot R. Mandibular subcondylar fracture accessibility with transparotid approach by rhytidectomy and modified Risdon approach: an anatomical comparative study. J Craniomaxillofac Surg 2018;46:225660. https://doi.org/10.1016/j.jcms.2018.10.011

14. Saylam C, Ucerler H, Orhan M, Ozek C. Anatomic landmarks of the buccal branches of the facial nerve. Surg Radiol Anat 2006;28:462-7. https://doi.org/10.1007/s00276-006-0127-7

15. Tang W, Gao C, Long J, Lin Y, Wang H, Liu L, et al. Application of modified retromandibular approach indirectly from the anterior edge of the parotid gland in the surgical treatment of condylar fracture. J Oral Maxillofac Surg 2009;67:552-8. https://doi. org/10.1016/j.joms.2008.06.066

16. Liu P, Li F, Peng L. An anatomical landmark for retromandibular transparotid approach to treat subcondylar fractures. J Craniofac Surg 2021;32:e427-9. https://doi.org/10.1097/ SCS.0000000000007233

17. Yabe T, Tsuda T, Hirose S, Ozawa T. Preauricular transparotid approach to mandibular condylar fractures without dissecting facial nerves. J Craniofac Surg 2013;24:1365-7. https://doi.org/10.1097/ SCS.0b013e318285d9a3

18. Draaijers LJ, Tempelman FR, Botman YA, Tuinebreijer WE, Middelkoop E, Kreis RW, et al. The patient and observer scar assessment scale: a reliable and feasible tool for scar evaluation. Plast Reconstr Surg 2004;113:1960-5; discussion 1966-7. https://doi. org/10.1097/01.prs.0000122207.28773.56

19. Kudur MH, Pai SB, Sripathi H, Prabhu S. Sutures and suturing techniques in skin closure. Indian J Dermatol Venereol Leprol 2009;75:425-34. https://doi.org/10.4103/0378-6323.53155

How to cite this article: Lee JS, Kang SH. Direct transparotid approach via a modified mini-preauricular incision for open reduction and internal fixation of subcondylar fractures. J Korean Assoc Oral Maxillofac Surg 2021;47:327-334. https://doi.org/10.5125/ jkaoms.2021.47.4.327 